\title{
A POSSIBILIDADE DE RETORNO ANTECIPADO AO TRABALHO DE EMPREGADOS EM GOZO DE BENEFÍCIO PREVIDENCIÁRIO AUXÍLIO DOENÇA
}

José de Oliveira Costa Filho, Aline Fonseca Franco

Universidade do Oeste Paulista - UNOESTE. Curso de Direito, Presidente Prudente - SP. E-mail: josefrancoecosta@gmail.com

\section{RESUMO}

O presente artigo objetiva discutir as legislações previdenciárias e trabalhistas, assim como entendimentos doutrinários e jurisprudenciais referentes ao benefício previdenciário de auxílio doença e seus reflexos no contrato de trabalho. Para tanto, se analisou a competência para decisão acerca da incapacidade laboral, da concessão e cessação do benefício previdenciário. Destacou-se ainda o tratamento doutrinário e dos tribunais superiores sobre a mitigação dos efeitos do contrato de trabalho frente à sua suspensão na vigência do auxílio doença. Ao final, em face do embasamento jurídico legal, permitiu-se concluir que a concessão da alta pela autarquia previdenciária é requisito obrigatório para que o trabalhador em gozo de auxílio doença retorne ao trabalho antes da data fixada para o final de seu benefício.

Palavras-chave: Previdência Social, auxílio-doença, alta, retorno trabalho, perícia medical

\section{THE POSSIBILITY OF EARLY RETURN TO WORK FOR EMPLOYEES RECEIVING AID PENSION BENEFIT DISEASE}

\begin{abstract}
This article discusses the social security and labor laws, as well as doctrinal and jurisprudential understandings relating to the aid pension benefit disease, and their reflections in the employment contract. For this, we analyzed the authority to decide about work disability, the granting and termination of the pension benefit. It was also highlighted doctrinal and superior courts treatment on mitigating the effects of the employment contract in front of his suspension term in aid disease. Finally, in light of the legal argument, if allowed to conclude that the grant of pension by the high authority is mandatory requirement for the enjoyment of worker aid disease return to work before the date set for the end of your benefit.
\end{abstract}

Keywords: Social Security, sick pay, high medical, return job, expertise medical 


\section{INTRODUÇÃO}

A motivação para o presente estudo assenta-se nos recorrentes atritos entre empregadores, trabalhadores e Previdência Social quando beneficiários de auxílio-doença desejam retornar ao trabalho antes da data fixada para o término de seu benefício. Essa situação deve-se ao motivo de alguns empregadores adotarem a conduta de não permitir o acesso do beneficiário ao ambiente de trabalho, antes da cessação do auxílio-doença pelo INSS, ao passo que outros preferem admitir o trabalhador na empresa, comunicando o retorno ao trabalho à Previdência Social para que o benefício seja cessado.

No primeiro caso, o trabalhador costuma ser orientado pelo empregador a procurar uma agência da Previdência Social, solicitando sua imediata alta do benefício previdenciário, o que viabilizaria seu desejo de retornar ao trabalho.

Porém, nem sempre a Previdência possui disponibilidade para atender imediatamente a solicitação do trabalhador, visto que a autarquia INSS exige para tanto uma nova Perícia Médico-Legal, a fim de comprovar a capacidade laboral do, até então, beneficiário. Dessa forma, considerando que em grande parte das vezes o trabalhador deseja retornar o mais rápido possível a seu posto de trabalho, o agendamento dessa nova avaliação para uma data futura, somado à nebulosidade acerca da real proibição do retorno ao trabalho sem a alta previdenciária, acaba gerando, muitas vezes, grandes infortúnios e atritos entre trabalhadores e empregadores, incluindo também às vezes, servidores das agências da Previdência Social.

O objetivo do presente trabalho, portanto, é a busca na legislação, literatura e jurisprudência brasileiras de uma resposta para adoção do correto procedimento pelos empregados, empregadores e pela Previdência Social diante dessas situações, afim de que sejam dirimidos os conflitos atualmente existentes.

\section{METODOLOGIA}

Para cumprir o objetivo proposto, o presente trabalho seguirá os métodos dialético-dedutivo, com emprego de pesquisa à legislação, doutrina e jurisprudência acerca da matéria objeto do estudo.

\section{RESULTADOS}

\section{DO BENEFÍCIO PREVIDENCIÁRIO AUXÍLIO DOENÇA}

Relativamente à problematização trazida, necessária uma abordagem inicial sobre o tratamento da legislação previdenciária (Lei 8213/91 e Decreto 3048/99), assim como os entendimentos doutrinários e jurisprudenciais acerca do benefício auxílio doença: 
Lei 8213 , de 24 de Julho de 1991

Art. 59. O auxílio-doença será devido ao segurado que, havendo cumprido, quando for o caso, o período de carência exigido nesta Lei, ficar incapacitado para o seu trabalho ou para a sua atividade habitual por mais de 15 (quinze) dias consecutivos.

Art. 60. O auxílio-doença será devido ao segurado empregado a contar do décimo sexto dia do afastamento da atividade, e, no caso dos demais segurados, a contar da data do início da incapacidade e enquanto ele permanecer incapaz.

Decreto 3048, de 6 de Maio de 1999.

Art. 71. O auxílio-doença será devido ao segurado que, após cumprida, quando for o caso, a carência exigida, ficar incapacitado para o seu trabalho ou para a sua atividade habitual por mais de quinze dias consecutivos.

Art. 78. O auxílio-doença cessa pela recuperação da capacidade para o trabalho, pela transformação em aposentadoria por invalidez ou auxílio-acidente de qualquer natureza, neste caso se resultar sequela que implique redução da capacidade para o trabalho que habitualmente exercia.
Conforme a norma retro transcrita, verifica-se que o benefício auxílio-doença é devido ao trabalhador que for afastado de suas atividades laborais, em virtude de estar incapacitado para seu trabalho.

Nesse sentido, vejamos 0 posicionamento de renomados doutrinadores:

"O auxilio doença é o benefício devido ao segurado que ficar incapacitado para o seu trabalho ou para atividade laboral, por mais de 15 dias consecutivos.".

(KERTZMAN, 2011, p. 413414).

“O auxilio doença é benefício não programado decorrente de incapacidade temporária do segurado para $O$ seu trabalho habitual. (IBRAHIM, 2008, p. 567)"

Da leitura dos referidos dispositivos normativos, constata-se que o benefício auxílio doença terá início no décimo sexto dia do afastamento da atividade, para os trabalhadores empregados e, nos demais casos, no dia do início da incapacidade laboral, sendo o fim do benefício, em todos os casos, estabelecido pela recuperação da capacidade laboral.

Nesse ponto, cumpre esclarecer, por relevante, a questão relativa à competência legal para avaliação da existência/inexistência da incapacidade 
laboral. Cita-se, para tanto, o previsto na Lei 10.876 de 2 de Junho de 2004, lei que cria a carreira de Perícia Médica da Previdência Social:

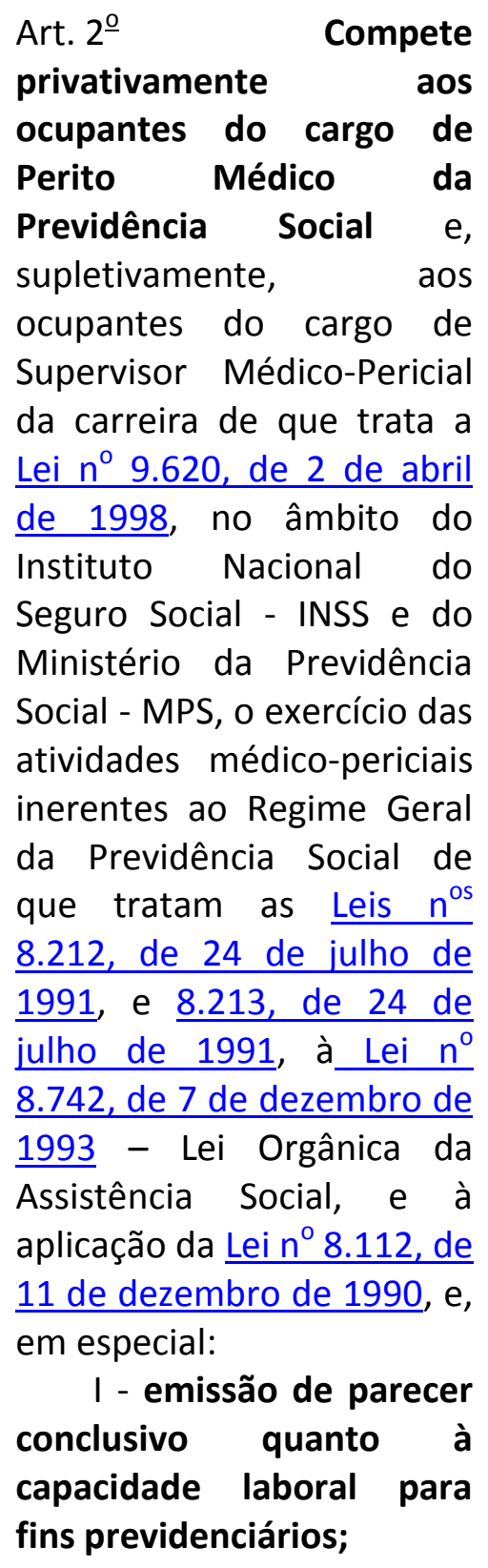

Importante citarmos também o previsto na Lei 605, de 5 de Janeiro de 1949, especialmente quanto ao afastamento por doença:

Art. 60 Não será devida a remuneração quando, sem motivo justificado, o empregado não tiver trabalhado durante toda a semana anterior, cumprindo integralmente o seu horário de trabalho.

$\S \quad 10$ São motivos justificados:

(...)

f) a doença do empregado, devidamente comprovada.

$\S$ 2 A doença será comprovada mediante atestado de médico da instituição da previdência social a que estiver filiado o empregado, e, na falta dêste e sucessivamente, de médico do Serviço Social do Comércio ou da Indústria; de médico da emprêsa ou por ela designado; de médico a serviço de representação federal, estadual ou municipal incumbido de assuntos de higiene ou de saúde pública; ou não existindo êstes, na localidade em que trabalhar, de médico de sua escôlha. (Redação dada pela Lei no 2.761, de 26.4.56)

Especificamente, sobre a competência da qual estamos tratando e da ordem de preferência disposta na Lei 605/49, art. 6ㅇ, § 2ำ, o Tribunal Superior do Trabalho já firmou entendimento, expresso na súmula $\mathrm{n} \cong 15$ abaixo transcrita, no sentido de que a ordem definida no parágrafo deve ser observada na determinação da competência da análise da incapacidade laboral. 
Súmula no 15 do TST

ATESTADO MÉDICO
(mantida) - Res. 121/2003,
DJ 19, 20 e 21.11.2003
A justificação da ausência
do empregado motivada
por doença, para a
percepção do salário-
enfermidade e da
remuneração do repouso
semanal, deve observar a
ordem preferencial dos
atestados médicos
estabelecida em lei.

Tal prerrogativa da Previdência Social fundamenta-se no princípio constitucional da supremacia do interesse público sobre o privado, uma vez que um trabalhador incapaz em atividade, pode constituir, eventualmente, um perigo à coletividade. Nesse ponto, necessária a atuação do Estado para inibir a exposição da sociedade a um potencial risco, garantindo a proteção coletiva e também individual.

Como defende Celso Antônio Bandeira de Mello (2007), o princípio da supremacia do interesse público sobre o privado constitui o axioma do regime jurídico administrativo e é pressuposto de uma ordem social estável, em que todos e cada um possam sentir-se garantidos e resguardados. Segundo o renomado doutrinador, o referido princípio é inerente à qualquer sociedade e representa condição de sua existência, sendo pressuposto lógico do convívio social.
Por sua vez, Di Pietro (2008) defende que a necessidade de satisfação dos interesses coletivos conduz à outorga de prerrogativas à Administração Pública, quer para limitar o exercício dos direitos individuais em benefício do bem estar coletivo, quer para prestação de serviços públicos, com fundamento no princípio da supremacia do interesse público sobre o privado.

\section{DO REFLEXOS DO AUXílIO DOENÇA NO CONTRATO DE TRABALHO}

O benefício de auxílio-doença garantido ao trabalhador empregado a partir do décimo sexto dia de afastamento impõe, conforme dita o art. 63 da Lei 8312/91, bem como no art. 80 do Decreto 3048/99, consequências na relação estabelecida entre o trabalhador e seu empregador, vejamos:

\section{Lei 8213/91}

\begin{tabular}{|c|c|}
\hline $\begin{array}{l}\text { Art. } 63.0 \\
\text { empregado em } \\
\text { auxílio-doença } \\
\text { considerado pela } \\
\text { como licenciado. } \\
\text { Decreto } 3048 / 99\end{array}$ & $\begin{array}{l}\text { seguradc } \\
\text { gozo de }\end{array}$ \\
\hline $\begin{array}{l}\text { Art. } 80 . \quad 0 \\
\text { empregado em } \\
\text { auxílio-doença }\end{array}$ & $\begin{array}{l}\text { segura } \\
\text { gozo }\end{array}$ \\
\hline
\end{tabular}

Nesse mesmo sentido, dispõe a legislação trabalhista, principalmente na redação do art. 476 do Decreto-Lei 5452 de 1ํ de Maio de 1943 - Consolidação das Leis 
do Trabalho - CLT, conforme a seguir transcrito:

CLT - Decreto-Lei 5452/43

Art. 476 - Em caso de segurodoença ou auxílio-enfermidade, o empregado é considerado em licença não remunerada, durante 0 prazo desse benefício.

Têm-se, portanto, que a legislação considera que o trabalhador em gozo de auxílio doença deve ser considerado licenciado do trabalho, sendo essa licença não remunerada, conforme esclarece o dispositivo da CLT acima reproduzido.

A licença sem vencimento, consequência do recebimento do auxílio doença, é tratada pela doutrina como hipótese de suspensão do contrato de trabalho, em virtude da desoneração do empregador do pagamento da remuneração ao empregado.

A respeito da definição do instituto da licença sem vencimento como suspensão do contrato de trabalho é vasta a doutrina que disciplina esse entendimento, vejamos:

Haverá interrupção quando o empregado deva ser remunerado normalmente, embora não preste serviços, contando-se também o seu tempo de serviço, mostrando a existência de uma cessação temporária e parcial dos efeitos do contrato de trabalho. $\mathrm{Na}$ suspensão, o empregado fica afastado, não recebendo salário, nem é contado o seu tempo de serviço, havendo a cessação temporária e total dos efeitos do contrato de trabalho. (MARTINS, 2009, p. 324-325)

[...] A suspensão, como o próprio nome indica, apenas suspende os efeitos do pacto laboral, subsistindo, todavia, o vínculo jurídico. Não há prestação de serviços, tampouco pagamento salarial. $O$ período da suspensão, outrossim, não é computado no tempo de serviço. ...Caracteriza-se a interrupção pela simples paralisação dos serviços; o empregado não presta serviços, mas o empregador paga seus salários; e o período de interrupção é computado no tempo de serviço. (ALMEIDA, 2008, p. 228-233)

Assim, conforme a determinação legal de que o empregado deva ser considerado licenciado sem remuneração durante o recebimento do auxílio doença, nos termos do previsto principalmente na CLT, verifica-se que o recebimento do benefício previdenciário é caso de suspensão do contrato de trabalho.

\section{DISCUSSÃO}

Em face do prescrito pela legislação retro citada e pelos entendimentos doutrinários, pode-se inferir de forma imediata que o benefício auxílio-doença é devido ao trabalhador que for afastado de 
suas atividades laborais, em virtude de estar incapacitado para seu trabalho.

Observa-se também que a presença da incapacidade laboral é ponto chave para manutenção do benefício estudado, ao passo que a verificação da recuperação da capacidade para o trabalho faz cessar a prestação ao segurado.

Outro ponto relevante a ser considerado é a competência privativa da Previdência Social para decidir sobre a existência/inexistência da incapacidade laboral e, por consequência, somente a ela é conferida a prerrogativa de conceder ou cessar o benefício auxílio-doença.

Corroborando tal inferência, cita-se dispositivo normativo que confere o dever à autarquia previdenciária de conceder benefício auxílio-doença ex officio quando da verificação da existência de um trabalhador incapaz ao trabalho, ou seja, mesmo sem o seu requerimento ou anuência:

\section{Decreto 3048/99}

Art. 76. A previdência social deve processar de ofício o benefício, quando tiver ciência da incapacidade do segurado sem que este tenha requerido auxíliodoença.

Uma vez que o art. 476 da CLT impõe licença não remunerada ao trabalhador em gozo de auxílio doença, haverá conforme já vimos, a suspensão do contrato de trabalho.
É nessa mesma linha o entendimento de Vólia Bomfim Cassar (2009) a respeito dos reflexos do benefício previdenciário sobre contrato de trabalho:

De acordo com o art. 59 da Lei no 8.213/91 c/c art. 476 da CLT a doença que acarrete 0 afastamento do empregado pode surtir dois efeitos no contrato de trabalho: pelos 15 primeiros dias acarreta a interrupção. A partir do 160 dia, inclusive, a doença importa na suspensão do contrato, momento a partir do qual o empregador estará desonerado do pagamento dos salários, que ficarão a cargo da Previdência Social. (CASSAR, 2009, p 770)

Sussekind (2001) tem entendimento no mesmo sentido e vai além em sua obra, quando afirma que "enquanto durar o benefício previdenciário, perdurará a inexecução contratual".

Dessa forma pode-se, sem maiores explanações, concluir que deve ser o contrato de trabalho do empregado em recebimento de auxílio doença considerado suspenso, desde o início do pagamento do benefício até a sua cessação pela Previdência Social.

Tribunais Superiores têm demonstrado, em lides com esse objeto, exegese concordante à doutrina acima destacada:

TST - RECURSO DE REVISTA

$R R \quad 208006320085040121$

20800-63.2008.5.04.0121

(TST)

Ementa: RECURSO DE REVISTA. PLANO DE SAÚDE. 
CONTRATO DE TRABALHO SUSPENSO EM RAZÃO DE AUXÍLIO-DOENÇA.

ACÓRDÃO DO E. TRT DA 4ạ

REGIÃO QUE MANTÉM A DETERMINAÇÃO DE

INCLUSÃO DA RECLAMANTE NAQUELE PLANO. VIOLAÇÃO DO ARTIGO 468 DA CLT. INEXISTÊNCIA. É pacífico $\mathrm{O}$ entendimento nesta Corte de que o direito à manutenção do plano de saúde depende da permanência do vínculo de emprego, e não da prestação de serviço. Ocorrendo a suspensão do contrato de trabalho, em razão do auxílio-doença, a reclamante continua a ser empregada, pelo que faz jus à permanência no plano de saúde. Recurso de revista não conhecido.

Amauri Mascaro Nascimento (2008) observa que a suspensão temporária como medida de proteção ao desemprego não é uma invenção brasileira, mas um instrumento praticado em diversos países há algum tempo, conforme recomendação da OIT através da Convenção n. 168 ratificada pelo Brasil mediante o Decreto-legislativo $n$. 89 , de $10 / 12 / 92$.

No período de suspensão do contrato de trabalho por auxílio doença, há a restrição no poder de resilição do empregador, pois, neste lapso temporal, os direitos e obrigações decorrentes do contrato de trabalho não subsistem em sua plenitude. A legislação somente confere $\mathrm{o}$ direito à demissão se verificada a justa causa, conforme entendimento majoritário:

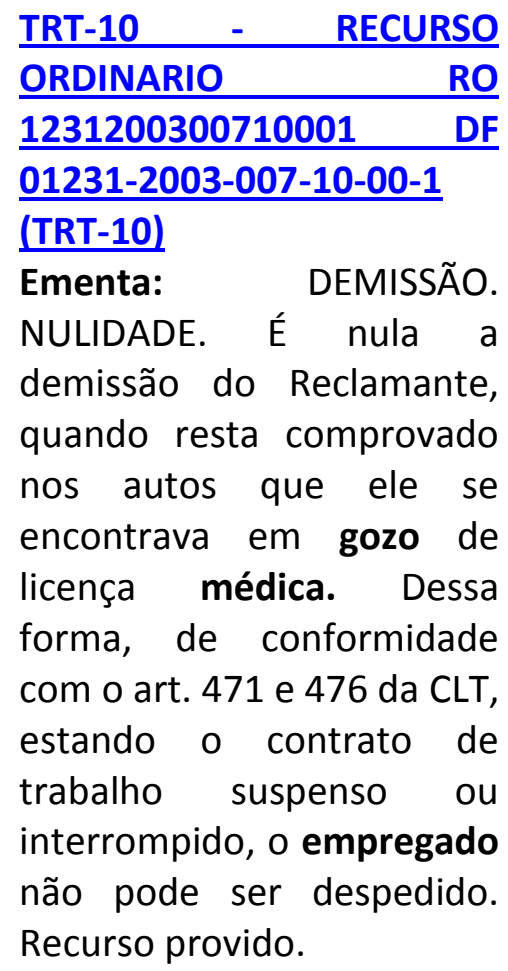

Nesse sentido, por consequência dessa mesma limitação de direitos e obrigações a empregadores e empregados durante a suspenção do contrato de trabalho, é que se impõe a conclusão de que ao empregado não assiste o direito de retorno espontâneo ao trabalho antes da data final fixada para cessação do benefício auxílio doença, assim como ao empregador não é imposta a obrigação de receber o empregado ainda em gozo do benefício previdenciário em sua função laboral, posto que os efeitos do contrato encontram-se suspensos até o final do benefício.

Ressalte-se, por final, que somente após o término do auxílio doença fixado pela Previdência Social e a consequente cessação da 
suspenção do contrato de trabalho é que ambos, empregado e empregador, terão seus direitos e obrigações restabelecidos em sua plenitude, a partir de quando poderão continuar sua relação jurídica pré-estabelecida.

\section{CONCLUSÃO}

De todo exposto, é pacífico que o trabalhador em gozo de auxílio-doença deve ser considerado licenciado do trabalho, sem remuneração, em vista da suspenção do contrato de trabalho.

Diante da suspenção do contrato de trabalho nessas condições, resta impedido o retorno do trabalhador à sua função, situação que permanecerá até o fim do benefício previdenciário fixado pela Autarquia Previdenciária, a qual possui prerrogativa plena e privativa na decisão sobre a capacidade laboral dos trabalhadores e, por consequência, sobre a concessão e cessação dos benefícios previdenciários por incapacidade.

Conclui-se assim, finalmente, que ainda que o trabalhador queira retornar ao trabalho, a alta do benefício previdenciário declarada pelo Instituto Nacional do Seguro Social - INSS é requisito obrigatório para que o empregador possa recebê-lo antes da data pré-fixada para a cessação de seu auxílio doença. Tal procedimento constitui um mecanismo de proteção à sociedade, observando-se o aspecto coletivo em detrimento a um direito individual.

\section{REFERÊNCIAS}

CASSAR, V. B.. Direito do Trabalho. 3.ed. Niterói-RJ: Impetus, 2009.

DI PIETRO, M. S. Z. Direito Administrativo. 21. ed. São Paulo: Atlas, 2008.

MELLO, C. A. B. Curso de direito

administrativo. 22. ed. rev. atual. São Paulo: Malheiros, 2007.

IBRAHIM, F. Z. . Curso de direito

previdenciário. 15. ed. Rio de Janeiro:

Impetus, 2010.

KERTZMAN, Ivan. Curso prático de direito previdenciário. 8. ed. Bahia: Podivm, 2011.

ALMEIDA, A.P. CLT Comentada. 5. ed. rev. atual. e ampl. São Paulo: Saraiva, 2008, p. 228-233.

NASCIMENTO, A.M. Curso de Direito do Trabalho. 23. ed. São Paulo: Saraiva, 2008.

MARTINS, S.P. Direito do Trabalho. 25. ed. São Paulo: Atlas, 2009. p. 324-325.

SUSSEKIND, A. et. al. Instituições de direito do trabalho.. São Paulo: LTR, 2001. v.1

Recebido para publicação em 17/08/2014

Revisado em 15/09/2014

Aceito em 18/09/2014 